\title{
French Swiss physicians' attitude toward palliative sedation: Influence of prognosis and type of suffering
}

\author{
M. BEAUVERD, M.D., ${ }^{1}$ M. BERNARD, M.A., ${ }^{1}$ T. CURRAT, M.A., ${ }^{1}$ S. DUCRET, R.N., ${ }^{1}$ \\ R.A. FOLEY, PH.D., M.Sc., ${ }^{1}$ G.D. BORASIO, M.D., ${ }^{1}$ D. BLONDEAU, PH.D., ${ }^{2}$ AND S. DUMONT, T.S., PH.D. ${ }^{3}$ \\ ${ }^{1}$ Palliative care service, Department of medicine, Centre Hospitalier Universitaire Vaudois, Lausanne, Switzerland \\ ${ }^{2}$ Faculty of Nursing, Laval University, Quebec City, Canada \\ ${ }^{3}$ School of Social Work, Laval University, Quebec City, Canada \\ (RECEIVED January 4, 2013; ACCEPTED February 10, 2013)
}

\begin{abstract}
Objective: Palliative sedation is a last resort medical act aimed at relieving intolerable suffering induced by intractable symptoms in patients at the end-of-life. This act is generally accepted as being medically indicated under certain circumstances. A controversy remains in the literature as to its ethical validity. There is a certain vagueness in the literature regarding the legitimacy of palliative sedation in cases of non-physical refractory symptoms, especially "existential suffering." This pilot study aims to measure the influence of two independent variables (short/ long prognosis and physical/existential suffering) on the physicians' attitudes toward palliative sedation (dependent variable).

Methods: We used a $2 \times 2$ experimental design as described by Blondeau et al. Four clinical vignettes were developed (vignette 1: short prognosis/existential suffering; vignette 2: long prognosis/existential suffering; vignette 3: short prognosis/physical suffering; vignette 4: long prognosis/physical suffering). Each vignette presented a terminally ill patient with a summary description of his physical and psychological condition, medication, and family situation. The respondents' attitude towards sedation was assessed with a six-point Likert scale. A total of 240 vignettes were sent to selected Swiss physicians.

Results: 74 vignettes were completed (36\%). The means scores for attitudes were $2.62 \pm 2.06$ (v1), $1.88 \pm 1.54(\mathrm{v} 2), 4.54 \pm 1.67$ (v3), and $4.75 \pm 1.71$ (v4). General linear model analyses indicated that only the type of suffering had a significant impact on the attitude towards sedation $(F=33.92, d f=1, p=0.000)$.

Significance of the results: The French Swiss physicians' attitude toward palliative sedation is more favorable in case of physical suffering than in existential suffering. These results are in line with those found in the study of Blondeau et al. with Canadian physicians and will be discussed in light of the arguments given by physicians to explain their decisions.
\end{abstract}

KEYWORDS: Palliative sedation, Existential suffering, End-of-life decision making, Switzerland

\section{INTRODUCTION}

Palliative sedation (PS) is defined as the use of specific sedative medications to relieve intolerable suffering from refractory symptoms by a reduction in patient consciousness (de Graeff \& Dean, 2007). In palliative medicine, PS is considered to be an im-

Address correspondence and reprint requests to: Michel Beauverd, Palliative Care Service, Centre Hospitalier Vaudois (CHUV), Hôpital Nestlé, Avenue Pierre Decker 5, 1011 Lausanne, Switzerland. E-mail: michel.beauverd@chuv.ch portant and ethically accepted treatment for a small selected group of patients (Morita et al., 2003; Cherny et al., 2009), with a reported prevalence between $2.5 \%$ to $16 \%$ of all deaths (Seale, 2009; Miccinesi et al., 2006; Chambaere et al., 2010; Jaspers et al., 2012). However, uncertainties exist regarding definition and practice of PS, which may be vulnerable to unskilled and abusive practices (Billings \& Block, 1996). Commonly accepted prerequisites for the initiation of PS include: the existence of intolerable suffering from refractory symptoms, the 
imminence of death, and the presence of an incurable disease. It is now widely accepted that PS does not hasten death (Maltoni et al., 2009; 2012a).

Psychological and existential distress as an indication for PS is a controversial issue (Boston et al., 2011; Materstvedt \& Bosshard, 2009). There is an emerging literature suggesting PS as a tolerable intervention for existential distress in case of refractory suffering. Muller-Busch et al. (2003) mentioned that palliative sedation is being increasingly administered to treat specific existential rather than physical suffering. Few empirical studies have been conducted about attitudes of care professionals toward palliative sedation taking existential suffering into account. Blondeau et al. (2005) conducted a study to measure the effect of prognosis (long vs. short-term) and the nature of suffering (physical vs. existential) on the attitudes of palliative care professionals towards PS (Blondeau et al., 2005). Their results indicated that sedation was considered to be an acceptable practice in case of intractable physical, but not existential suffering, irrespective of the temporal prognosis.

The purpose of this study is two-fold. First, to explore, in the French part of Switzerland, physicians' attitudes toward palliative sedation. Second, to specifically highlight the most significant physicians' motives associated to their acceptance or rejection of palliative sedation according to the type of prognosis and suffering. In order to do so, the same research design used by Blondeau et al. (2005) was employed.

\section{METHODS}

\section{Design and Outcome Measure}

This pilot study replicated the same $2 \times 2$ experimental design developed by Blondeau et al. (2005). A different combination of the two independent variables (prognosis and suffering) was used. Four clinical vignettes were developed (vignette 1: short prognosis $(<10$ days)/existential suffering; vignette 2: long prognosis (4 to 8 weeks)/existential suffering; vignette 3 : short prognosis $(<10$ days)/physical suffering; vignette 4: long prognosis ( 4 to 8 weeks)/physical suffering). Each vignette presented a terminally ill cancer patient with a summary description of his physical and psychological condition, medication, and family situation (see Appendix 1). The respondents' attitude toward sedation was assessed with a six-point Likert scale from 1 (strongly disagree = dis-favorable attitude toward sedation) to 6 (strongly agree $=$ favorable attitude toward sedation). Participants were requested to specify their position in written comments.

The "physical suffering" vignettes described a severe therapy-refractory physical symptom (no- ciceptive visceral pain and neuropathic pain, respectively). The "existential suffering" vignettes described in both cases a deep existential distress due to increasing despondence, a loss of meaning in life/sense of dignity in life, and a repeated wish to die. This was clearly differentiated from depression, and the patients retained full decision-making capacity. A content validity analysis of the vignettes was performed in Canada by three palliative care physicians (the original vignettes are available from the author on request). The research protocol and the consent forms were approved by the research ethics committee of the University of Lausanne.

\section{Participant Recruitment}

Physicians working regularly with palliative patient in the French part of Switzerland were selected from palliative care units, palliative care mobile team, rehabilitations centers with palliative care beds. General practitioners were selected on the basis of their affiliation to the Swiss Society of Medicine and Palliative Care. In total, 201 physicians were selected for the study. Each participant was randomly assigned to receive one of the four vignettes. Beside the clinical vignette, each clinician received by mail an information document and a signed consent form. The signed consent form and the study documents had to be returned in two separate envelopes in order to guarantee the respondent's confidentiality.

\section{Statistical Analysis}

General linear model analyses were calculated to measure both the impact of each independent variable (existential/physical suffering and short/long term prognosis) and the effect of their interaction on the physicians' attitude toward sedation. All analyses were computed using the statistical software SPSS 20.0.

Two independent coders analyzed the written comments by specifically selecting the personal motives warranting either agreement or disagreement with PS. Textual responses were unified to units of meaning. No specific software was used.

\section{RESULTS}

\section{Participants}

Of the 201 selected physicians, (77) 74 (36\%) completed both the clinical vignette and the signed consent form. (56) $57 \%$ of the respondents were men. Twelve percent of the physicians were younger than 36 years, $20 \%$ were between 36 and 45 years old, (31) $32 \%$ between 46 and 55 years old, and $33 \%$ were older 
than 56 years. (29) $26 \%$ of physicians had less than 6 years of clinical experience in palliative care, $20 \%$ had between 6 and 10 years of experience, $14 \%$ between 11 and 16 years of experience, and $27 \%$ more than 16 years of experience (with $14 \%$ missing data for this question).

The number of respondents per subgroup in accordance with the types of vignettes was the following: 13 respondents completed vignette 1 (short prognosis/ existential suffering), 17 completed vignette 2 (long prognosis/existential suffering), 24 completed vignette 3 (short prognosis/physical suffering); and 20 completed vignette 4 (long prognosis/physical suffering). The analyses (Chi square tests) indicated that the four groups were equivalent to each other with respect to age, sex, experience in palliative care, and clinical environment.

\section{Attitude toward Sedation}

With respect to physical suffering, physicians' attitudes toward sedation tended to be favorable, regardless of whether the prognosis was for the short-term $(M=4.54, S D=1.67)$ or the long-term $(M=4.75$, $S D=1.71$ ). With respect to existential suffering, physicians' attitudes toward sedation tended to be unfavorable, regardless of whether the prognosis was for the short-term $(M=2.62, S D=2.06)$ or the long-term $(M=1.88, S D=1.54)$. The analysis of variance using general linear models showed that only the type of suffering had a significant impact on the attitude toward sedation $(F=33.92, d f=1, p=$ $0.000)$. Neither the prognosis $(F=0.406, d f=1$, $p=0.526)$ nor the interaction between prognosis and type of suffering $(F=1.308, d f=1, p=0.257)$ influenced the physicians' attitudes. Figure 1

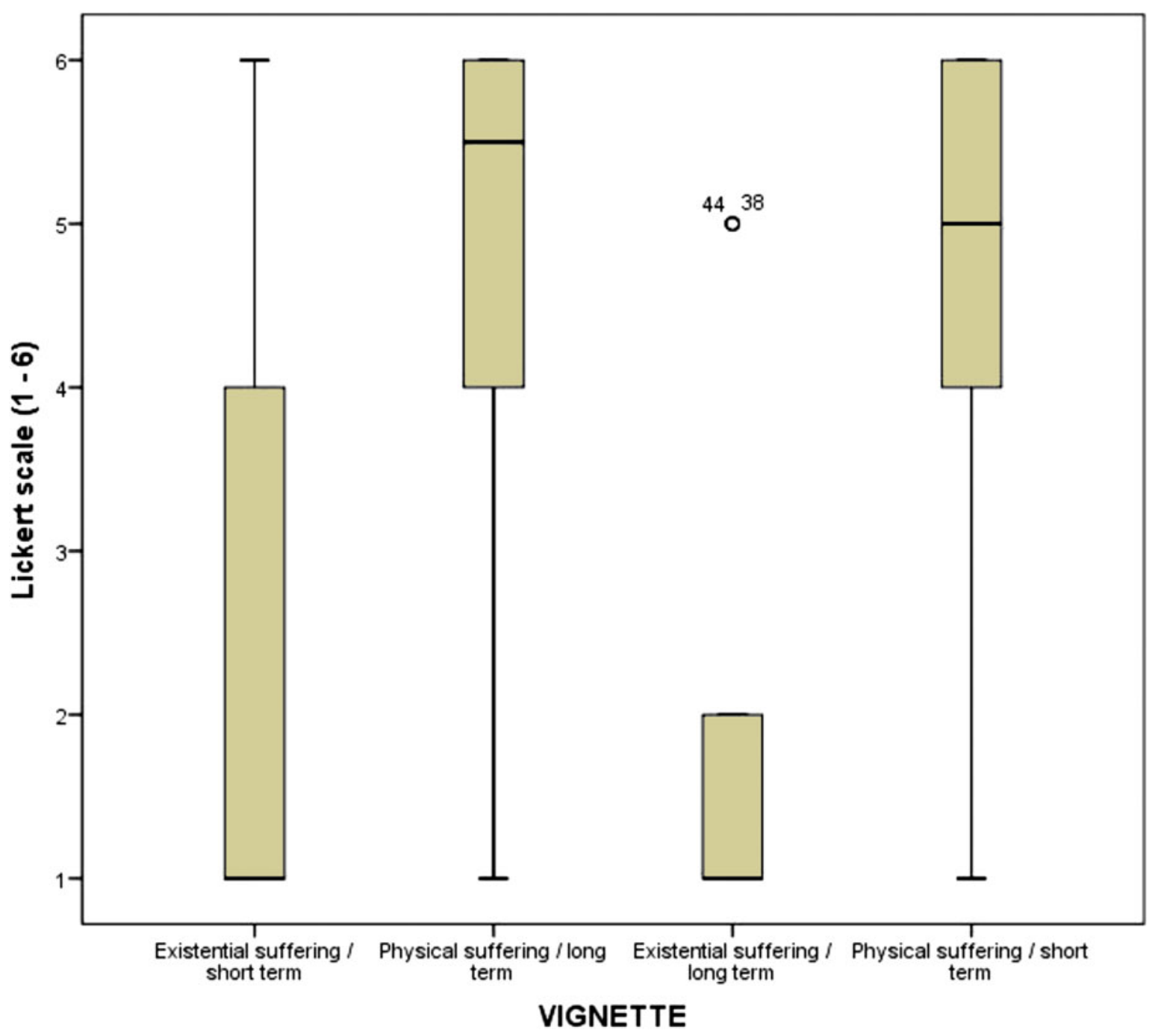

Fig. 1. Distribution of the scores reflecting the physicians' attitudes toward sedation according to the four vignettes from 1 (strongly disagree $=$ dis-favorable attitude toward sedation) to 6 (strongly agree $=$ favorable attitude toward sedation). 
Table 1. Motives linked to the physicians' attitudes towards terminal sedation according to the four vignettes

\begin{tabular}{|c|c|c|c|}
\hline $\begin{array}{l}\text { Type of suffering and } \\
\text { prognosis and attitude }\end{array}$ & $\begin{array}{c}\text { Motives cited more than } 5 \\
\text { times }\end{array}$ & Motives cited at least twice & Motives cited once \\
\hline $\begin{array}{l}\text { Existential suffering/ } \\
\text { short term } \\
\text { prognosis } \\
\text { Unfavorable } \\
\text { attitude }\end{array}$ & $\begin{array}{l}\text { - Palliative sedation is not } \\
\text { appropriate for } \\
\text { existential suffering } \\
\text { - Palliative sedation is not } \\
\text { clearly required by the } \\
\text { patient } \\
\text { - The view of the care } \\
\text { team was not considered }\end{array}$ & $\begin{array}{l}\text { - The view of the family } \\
\text { or relatives was not } \\
\text { considered } \\
\text { - Physical symptoms are } \\
\text { under control }\end{array}$ & $\begin{array}{l}\text { - Aim of the sedation was } \\
\text { not clear: dying or } \\
\text { relieving? } \\
\text { - The patient is enclosed by } \\
\text { his family } \\
\text { - No dissatisfaction was } \\
\text { addressed to the care } \\
\text { team } \\
\text { - Palliative sedation would } \\
\text { be detrimental to } \\
\text { communication with the } \\
\text { patient }\end{array}$ \\
\hline $\begin{array}{l}\text { Existential suffering/ } \\
\text { long term prognosis } \\
\text { Unfavorable } \\
\text { attitude }\end{array}$ & 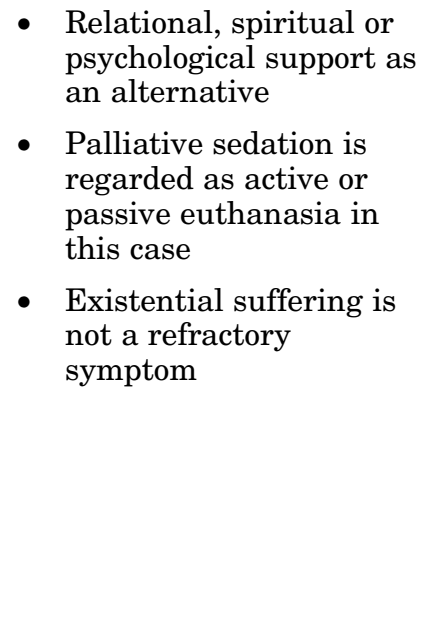 & $\begin{array}{l}\text { - The view of the family } \\
\text { or relatives was not } \\
\text { considered } \\
\text { - Testing another } \\
\text { medication as an } \\
\text { alternative }\end{array}$ & $\begin{array}{l}\text { - Palliative sedation is } \\
\text { painful for a health care } \\
\text { team } \\
\text { - Physical symptoms are } \\
\text { under control } \\
\text { - Care management is } \\
\text { difficult in case of } \\
\text { palliative sedation with a } \\
\text { long prognosis } \\
\text { - Intermittent sedation as } \\
\text { an alternative } \\
\text { - Prognosis is too long } \\
\text { - Waiting as an alternative } \\
\text { - Assisted suicide as an } \\
\text { alternative }\end{array}$ \\
\hline $\begin{array}{l}\text { Physical suffering/ } \\
\text { short term } \\
\text { prognosis Favorable } \\
\text { attitude }\end{array}$ & $\begin{array}{l}\text { - Physical symptom is } \\
\text { refractory to medication } \\
\text { treatment }\end{array}$ & $\begin{array}{l}\text { - The patient has his } \\
\text { capacity for } \\
\text { discernment } \\
\text { - The patient requires } \\
\text { himself a stop of the } \\
\text { chemotherapy and } \\
\text { palliative care }\end{array}$ & $\begin{array}{l}\text { - The prognosis is short } \\
\text { - The patient had a fulfilled } \\
\text { life }\end{array}$ \\
\hline $\begin{array}{l}\text { Physical suffering/ } \\
\text { long term prognosis } \\
\text { Favorable attitude }\end{array}$ & $\begin{array}{l}\text { - Physical symptom is } \\
\text { refractory to medication } \\
\text { treatment } \\
\text { - Palliative sedation } \\
\text { corresponds to the } \\
\text { patient's wishes } \\
\text { - Opportunity of an } \\
\text { intermittent sedation }\end{array}$ & $\begin{array}{l}\text { - The prognosis is } \\
\text { inevitable }\end{array}$ & $\begin{array}{l}\text { - The patient is treated in a } \\
\text { specialized palliative unit } \\
\text { - The patient had a fulfilled } \\
\text { life }\end{array}$ \\
\hline
\end{tabular}

illustrates the difference in the physicians' attitudes according to the type of suffering and the type of prognosis.

\section{Written Comments}

An analysis of the written comments was done by highlighting the motives specified by the physicians 
to explain their point of view. The number of motives varied between one and six according to the physicians. Only three physicians did not report any justification to explain their position toward PS but wrote general considerations about their conception of palliative care. The motives are reported in Table 1.

\section{DISCUSSION}

The response rate was globally low (36\%). No explicit reason was found; the time required to read the vignette and complete the questionnaire may have been a hindrance. The response rate was lower for the two vignettes related to existential suffering than for physical suffering. It is possible that these specific vignettes may cause some unease and raise questions that could discourage participation in the study. Interestingly, more written motives were listed when doctors answered to the vignettes regarding existential suffering compared to those regarding physical suffering.

\section{Existential Suffering}

In the case of existential suffering, physicians seem slightly less opposed to PS in case of short-term prognosis. A repeated argument against PS refers to the fact that the "refractory nature" of a symptom cannot be applied to existential suffering. Apparently, physicians have difficulty to assume the responsibility for prescribing a pharmacological solution for the relief of existential distress. Indeed, medical recommendations on PS are still very cautious regarding existential distress, whereas the definition of refractory symptoms employed in these papers clearly includes all types of suffering (Cherny \& Portenoy, 1994; Cherny et al., 2009). De Graeff and Dean (2007) state that "palliative sedation therapy for psychological or existential distress should be initiated only under exceptional circumstances and only after consultations with experts in this area." This last point is also mentioned in the two proposed guidelines specifically addressing palliative sedation in case of existential suffering (Rousseau, 2001; Schuman-Olivier et al., 2008). However, the mention of a psychiatric expertise excluding a depression in our existential suffering/long-term prognosis vignette did not appear to influence the negative attitude of the responding physicians. This may be explained by the fact that one of the most cited motives for the refusal of PS in our study is the purported association between PS and active euthanasia (Billings \& Block, 1996; Janssens et al., 2012; Raus et al., 2012).

In general, the free comments revealed widespread perceptions by the physicians of feeling lost and not competent enough when assessing and treat- ing existential suffering, as has been already reported in several papers on the subject (Blondeau et al., 2005; Cherny \& Portenoy, 1994). This perception may well have an influence on the willingness of the responding physicians to approve the initiation of PS in the cases described.

\section{Physical Suffering}

For both the vignettes based on physical suffering, physicians are rather favorable to PS, independently of the prognosis. The two major motives mentioned by the physicians are the refractory nature of the physical symptoms and the fact that sedation would be congruent with the patient's wishes. Discussing the ethical principles involved in PS in the case of physical suffering, Blondeau et al. (2005) mention the principles of beneficence, proportionality (which requires that the benefit outweighs the detriment), respect of autonomy and also the law of double effect as possible justifications to initiate sedation. The main motives cited by the Swiss respondents referred principally to beneficence and respect of autonomy. However, the sole view of the patient tended to be perceived as insufficient to justify the initiation of PS: physicians in Switzerland and Canada often quoted the opinion of the relatives and of the care team as being important in this context (Maltoni et al., 2012b).

This study has several limitations, including (1) the modest response rate, (2) the clear separation of the concepts of physical and existential suffering in the vignettes, which is rarely the case in daily clinical practice, and (3) the fact that only the prognosis and the type of suffering were considered as variables for this study. Nevertheless, our data show a remarkable congruence with the results of the Canadian study. This indicates a general agreement with the practice of PS for refractory physical symptoms, as well as a general uneasiness of physicians on both sides of the Atlantic with the prescription of PS for existential suffering. Subsequent phases of our research program will explore and analyze in more depth similarities and divergences observed in both jurisdictions. A qualitative analysis based on semi-structured interviews with study participants is ongoing in order to analyze the variety of discourses on PS in relation to different contexts of care.

\section{REFERENCES}

Billings, J.A. \& Block, S.D. (1996). Slow euthanasia. Journal of Palliative Care, 12, 21-30.

Blondeau, D., Roy, L., Dumont, S., et al. (2005). Physicians' and pharmacists' attitudes toward the use of sedation at the end of life: influence of prognosis and type of suffering. Journal of Palliative Care, 21, 238-245. 
Boston, P., Bruce, A. \& Schreiber, R. (2011). Existential suffering in the palliative care setting: An integrated literature review. Journal of Pain and Symptom Management, 41, 604-618.

Chambaere, K., Bilsen, J., Cohen, J., et al. (2010). Continuous deep sedation until death in Belgium: A nationwide survey. Archives of Internal Medicine, 170, 490-493.

Cherny, N.I. \& Portenoy, R.K. (1994). Sedation in the management of refractory symptoms: Guidelines for evaluation and treatment. Journal of Palliative Care, 10, $31-38$.

Cherny, N.I., Radbruch, L. \& Board of the European Association for Palliative. (2009). European Association for Palliative Care (EAPC) recommended framework for the use of sedation in palliative care. Palliative Medicine, 23, 581-593.

de Graeff, A. \& Dean, M. (2007). Palliative sedation therapy in the last weeks of life: A literature review and recommendations for standards. Journal of Palliative Medicine, 10, 67-85.

Janssens, R., van Delden, J.J. \& Widdershoven, G.A. (2012). Palliative sedation: Not just normal medical practice. Ethical reflections on the Royal Dutch Medical Association's guideline on palliative sedation. Journal of Medical Ethics, 38, 664-668.

Jaspers, B., Nauck, F., Lindena, G., et al. (2012). Palliative sedation in Germany: how much do we know? A prospective survey. Journal of Palliative Medicine, 15, 672-680.

Maltoni, M., Pittureri, C., Scarpi, E., et al. (2009). Palliative sedation therapy does not hasten death: Results from a prospective multicenter study. Annals of Oncology, 20, 1163-1169.
Maltoni, M., Scarpi, E., Rosati, M., et al. (2012a). Palliative sedation in end-of-life care and survival: A systematic review. Journal of Clinical Oncology, 30, 1378-1383.

Maltoni, M., Scarpi, E., Rosati, M., et al. (2012b). Palliative sedation in end-of-life care and survival: A systematic review. Journal of Clinical Oncology, 30, 1378-1383.

Materstvedt, L.J. \& Bosshard, G. (2009). Deep and continuous palliative sedation (terminal sedation): Clinicalethical and philosophical aspects. Lancet Oncology, 10, 622-627.

Miccinesi, G., Rietjens, J.A., Deliens, L., et al. (2006). Continuous deep sedation: Physicians' experiences in six European countries. Journal of Pain and Symptom Management, 31, 122-129.

Morita, T., Tei, Y. \& Inoue, S. (2003). Ethical validity of palliative sedation therapy. Journal of Pain and Symptom Management, 25, 103-105.

Muller-Busch, H.C., Andres, I. \& Jehser, T. (2003). Sedation in palliative care - A critical analysis of 7 years experience. BMC Palliative Care, 2, 2.

Raus, K., Sterckx, S. \& Mortier, F. (2012). Continuous deep sedation at the end of life and the 'natural death' hypothesis. Bioethics, 26, 329-336.

Rousseau, P. (2001). Existential suffering and palliative sedation: A brief commentary with a proposal for clinical guidelines. The American Journal of Hospice \& Palliative Care, 18, 151-153.

Schuman-Olivier, Z., Brendel, D.H., Forstein, M., et al. (2008). The use of palliative sedation for existential distress: A psychiatric perspective. Harvard Review of Psychiatry, 16, 339-351.

Seale, C. (2009). End-of-life decisions in the UK involving medical practitioners. Palliative Medicine, 23, 198-204. 